\title{
Supporting Information \\ Reaction between Graphene Oxide and Intracellular Glutathione Affects Cell Viability and Proliferation
}

Baojin Ma, Shi Guo, Yuta Nishina, Alberto Bianco*

B. Ma, S. Guo, A. Bianco

CNRS, Immunology, Immunopathology and Therapeutic Chemistry, UPR3572, University of

Strasbourg, ISIS, Strasbourg, 67000, France

E-mail: a.bianco@,ibmc-cnrs.unistra.fr

Y. Nishina

Graduate School of Natural Science and Technology, Okayama University, Tsushimanaka, Kita-ku, Okayama, 700-8530, Japan

Research Core for Interdisciplinary Sciences, Okayama University, Tsushimanaka, Kita-ku,

Okayama, 700-8530, Japan 

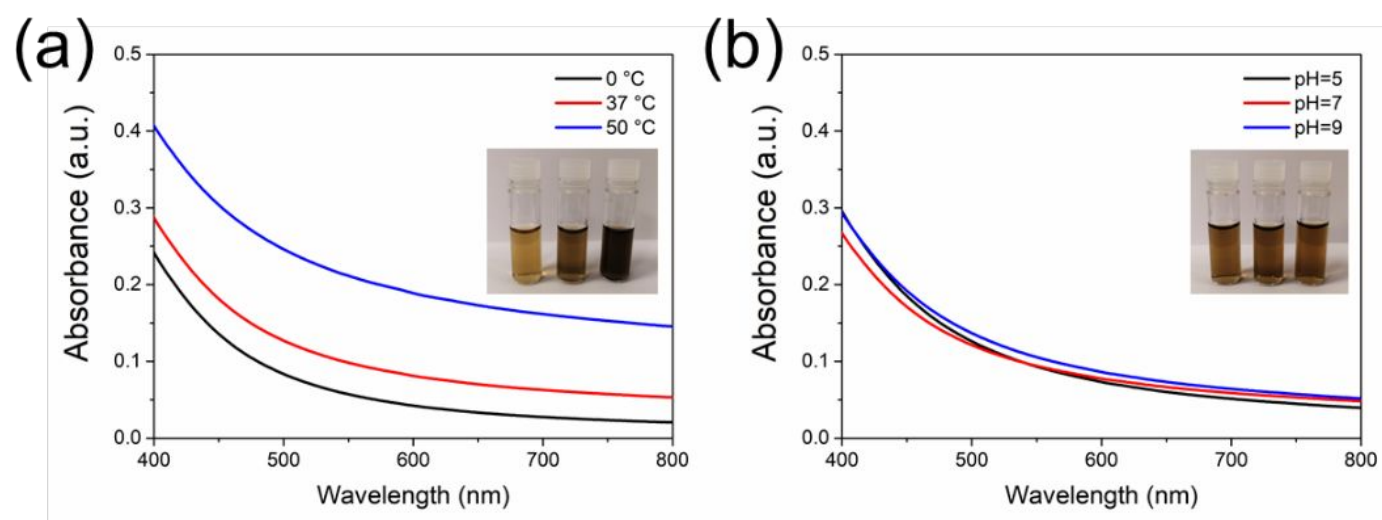

Figure S1. Color and absorbance changes of GO after reaction with GSH at different conditions. (a)

Different temperature after $3 \mathrm{~h}(\mathrm{pH}=5)$. (b) Different $\mathrm{pH}$ after $3 \mathrm{~h}\left(\mathrm{~T}=37^{\circ} \mathrm{C}\right)$.

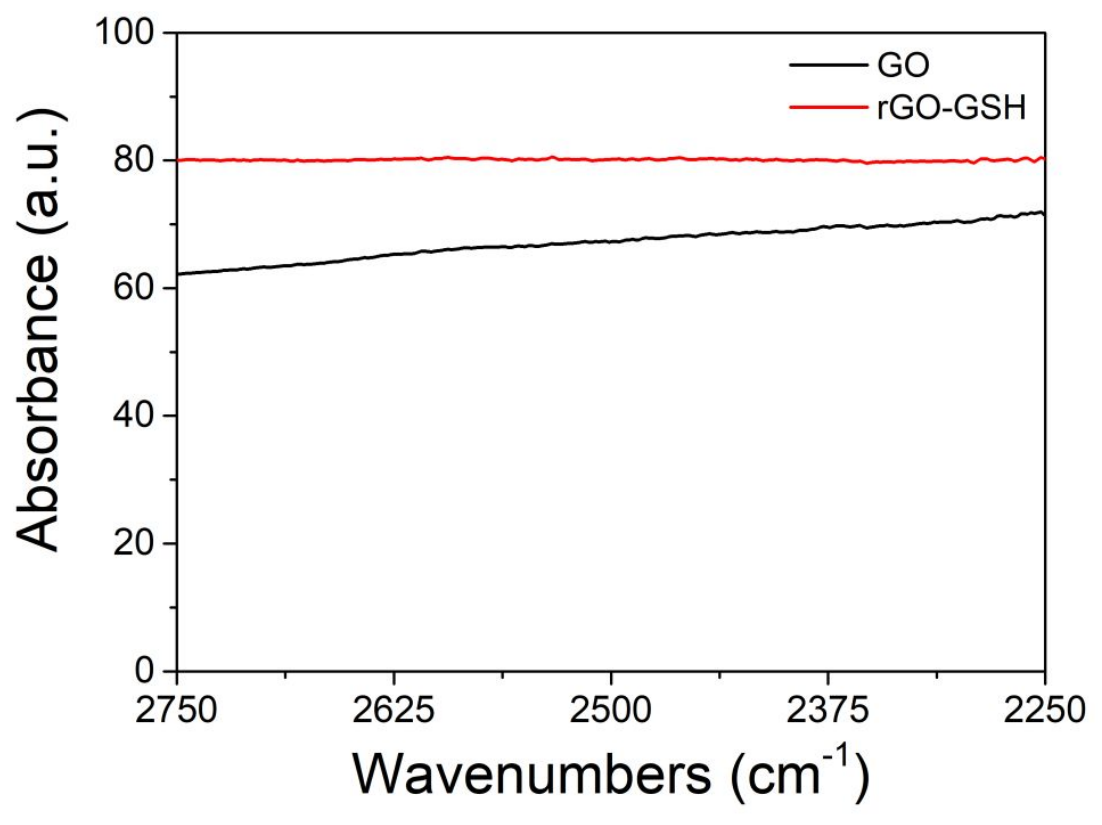

Figure S2. The magnification region of FT-IR spectra of GO and rGO-GSH to show the location of stretching band of thiol groups. 


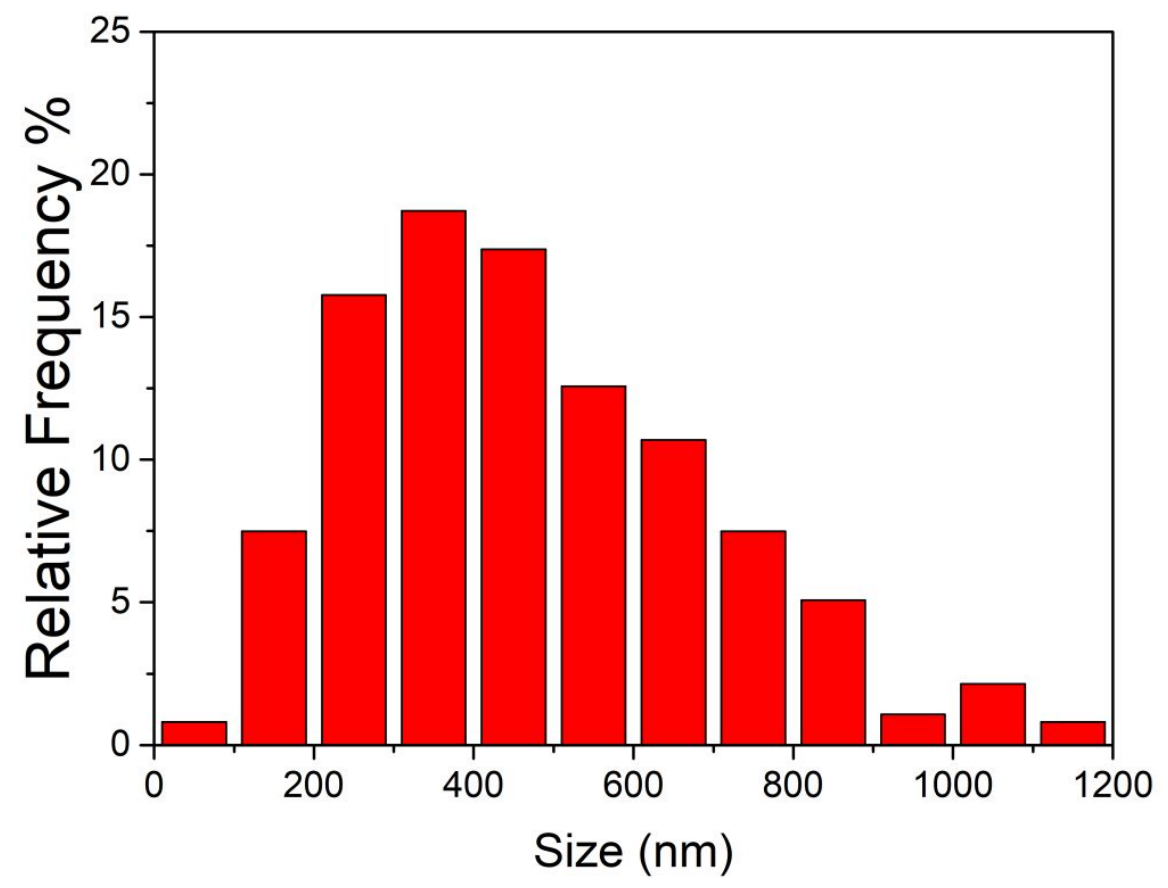

Figure S3. The size distribution of GO.

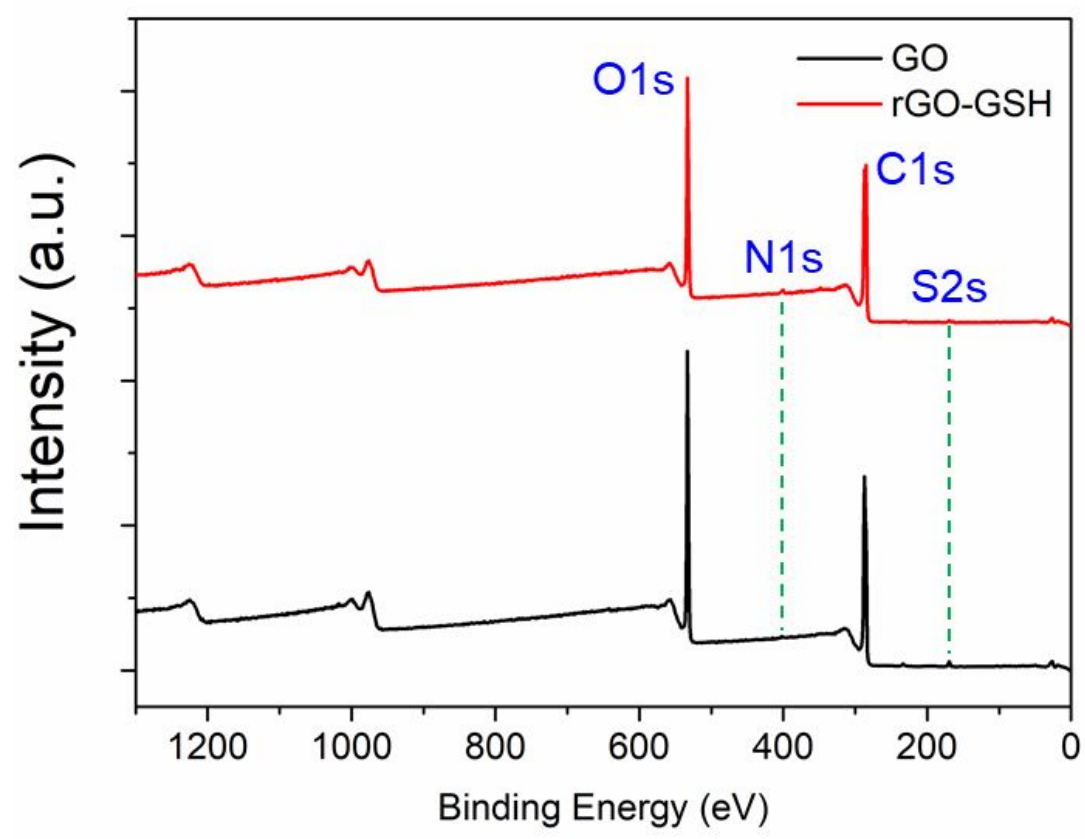

Figure S4. XPS survey spectra of GO and rGO-GSH. 

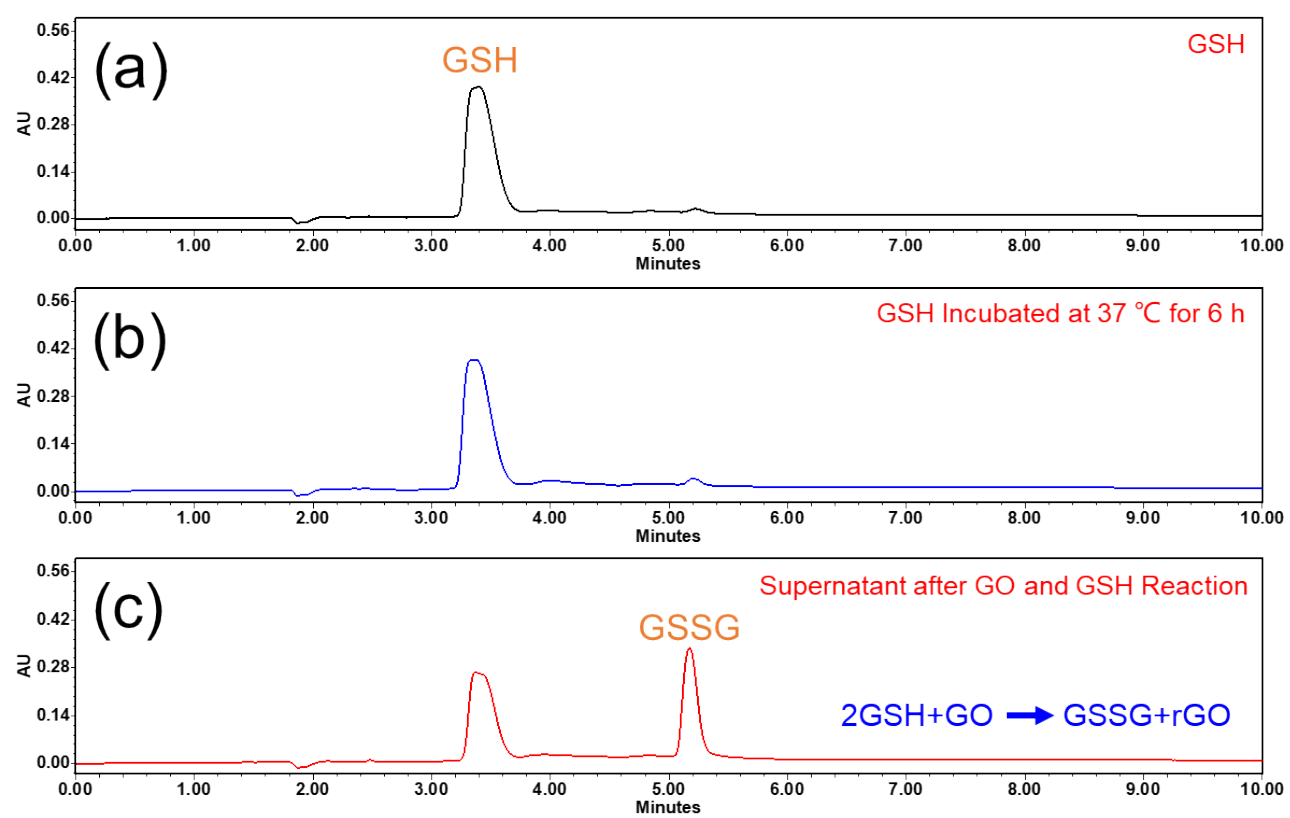

Figure S5. HPLC analysis of reaction products from supernatant. (a) GSH. (b) GSH incubated at $37{ }^{\circ} \mathrm{C}$ for $6 \mathrm{~h}$. (c) Supernatant after GO and GSH reaction at $37^{\circ} \mathrm{C}$ for $6 \mathrm{~h}$.

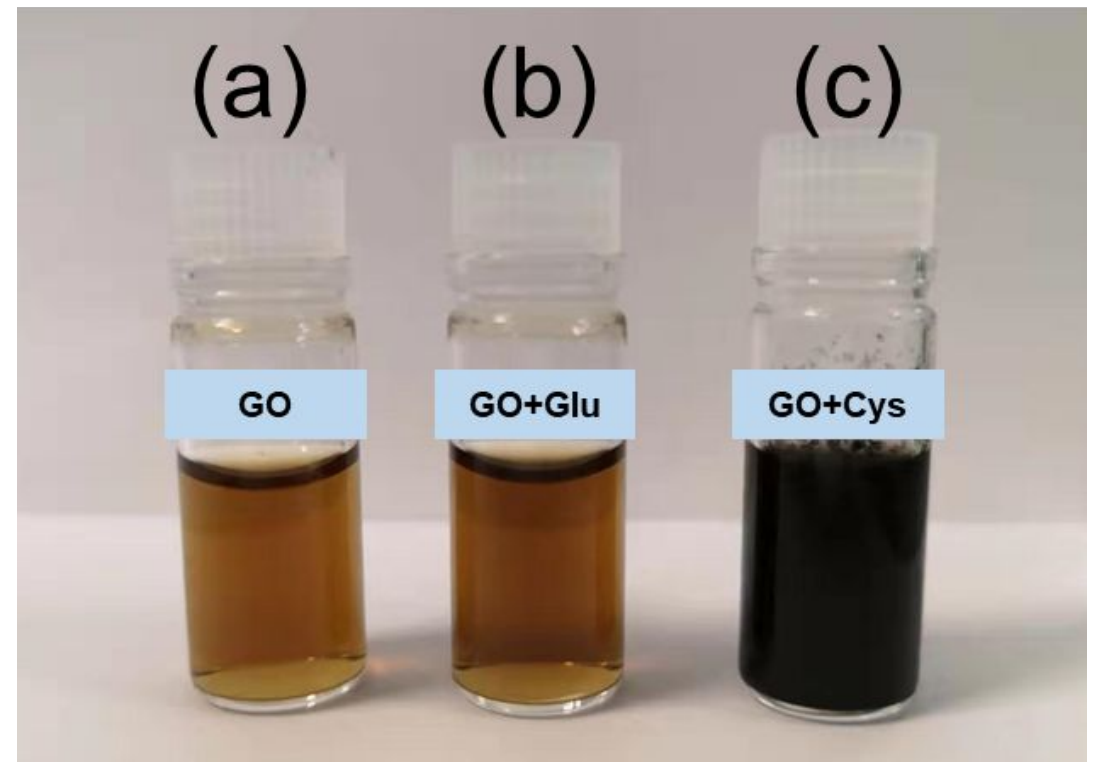

Figure S6. Optical images GO after reaction with glutamate or cysteine, respectively. (a) GO solution. (b) GO mixed with glutamate. (c) GO mixed with cysteine. 

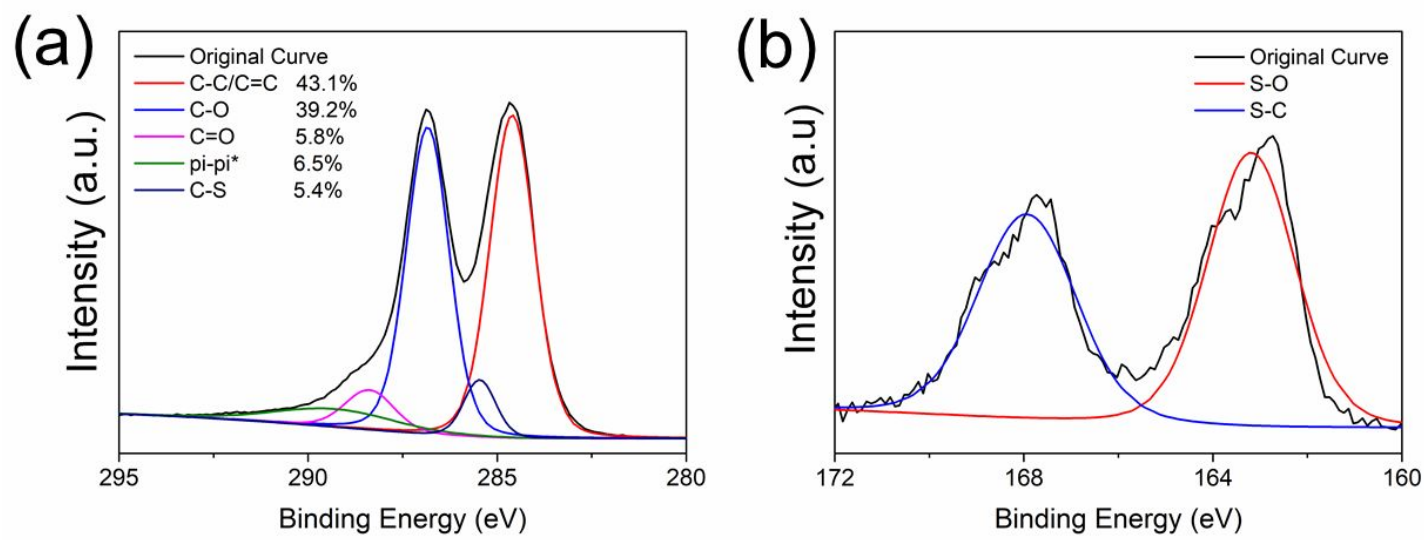

Figure S7. High resolution XPS spectra of rGO after reacted with cysteine. (a) High-resolution C1s. (b)

High-resolution S2p.
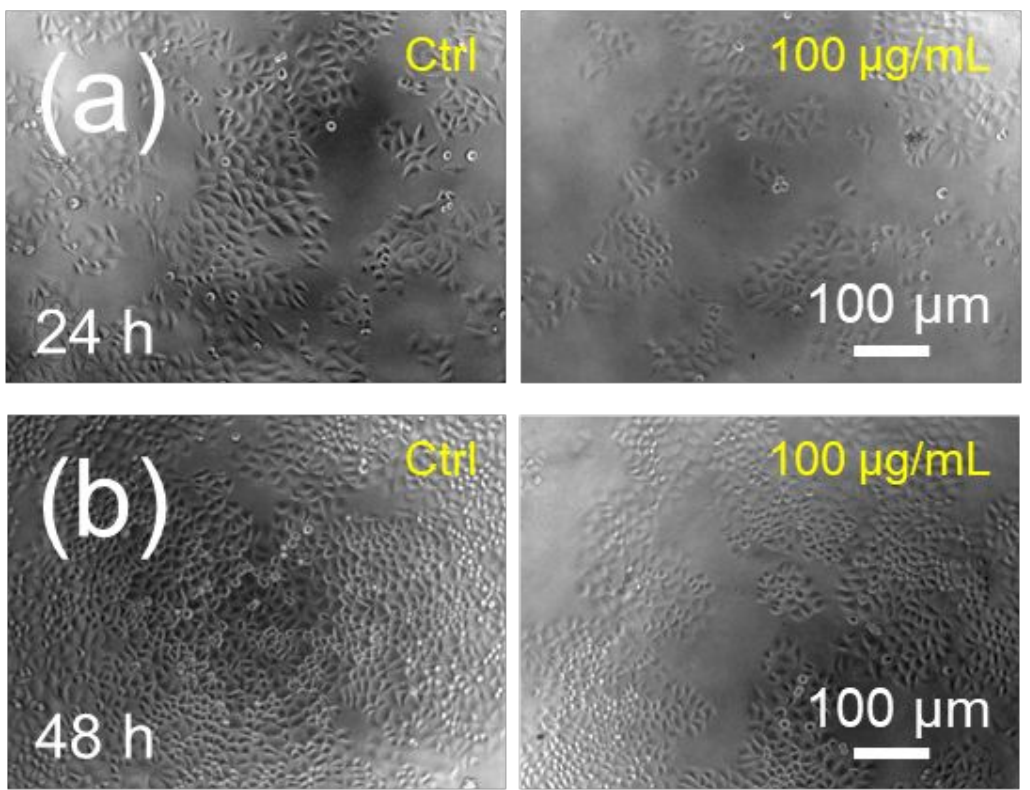

Figure S8. Bright field images of HeLa cells under $100 \mu \mathrm{g} / \mathrm{mL}$ concentration of GO after $24 \mathrm{~h}$ (a) and $48 \mathrm{~h}$

(b), respectively. 


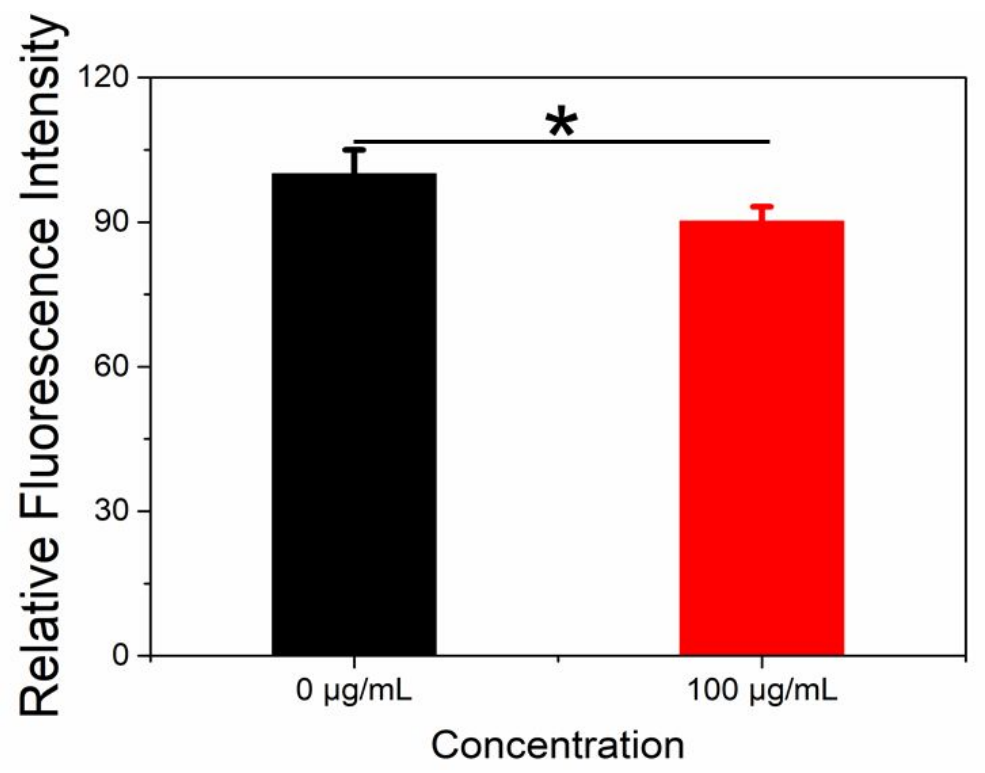

Figure S9. The relative fluorescence intensity of live cells.
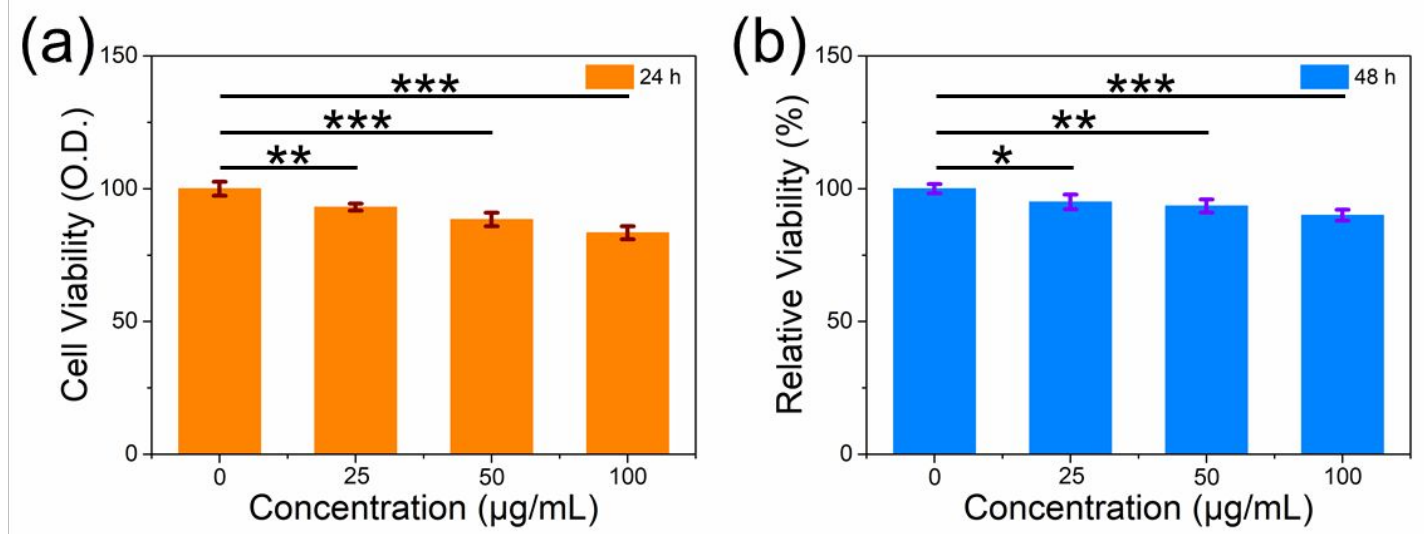

Figure S10. Viability of MCF-7 cells treated with GO at different concentrations after $24 \mathrm{~h}$ (a) and $48 \mathrm{~h}$ (b). 

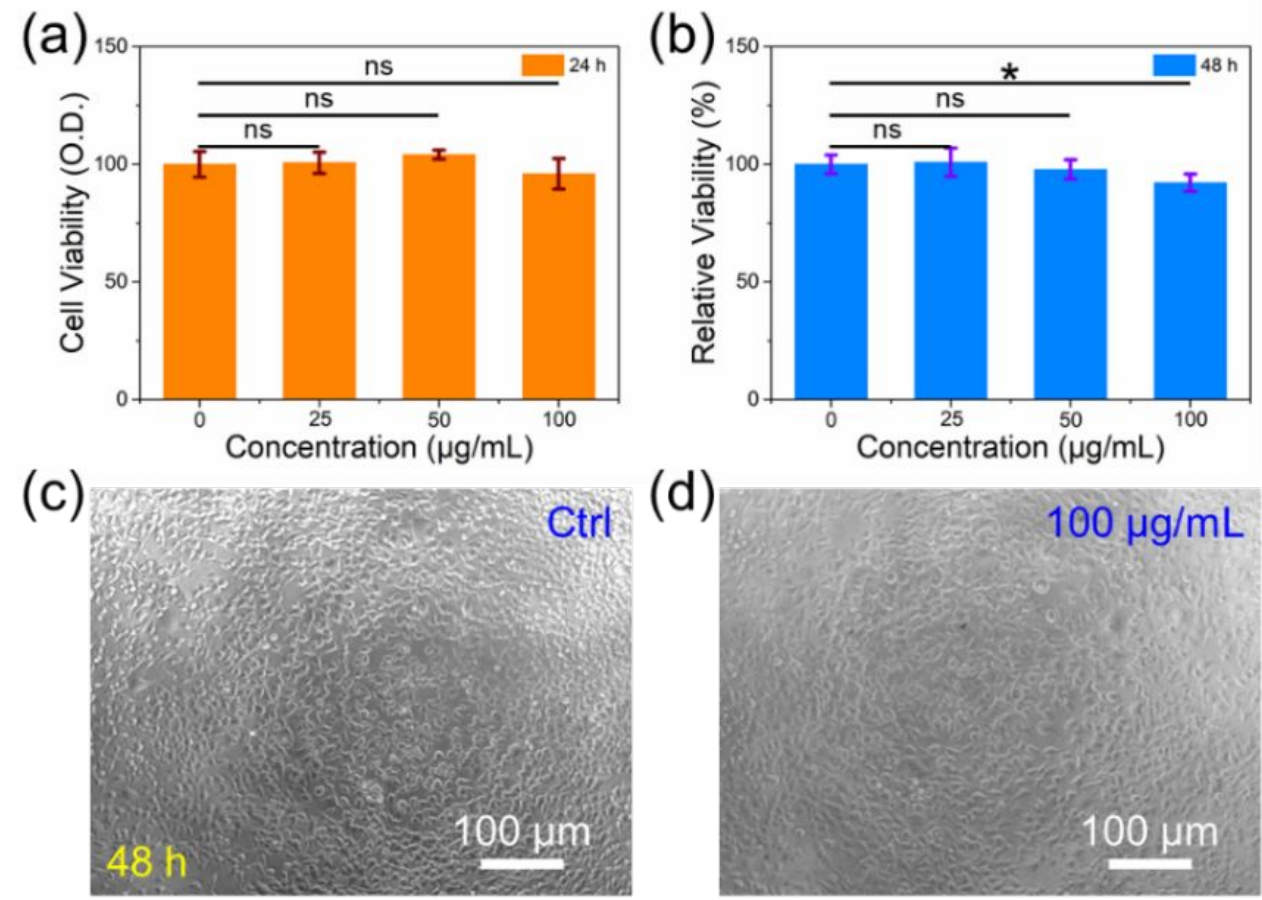

Figure S11. Viability of $\mathrm{HaCaT}$ cells treated with GO at different concentrations after $24 \mathrm{~h}$ (a) and $48 \mathrm{~h}$ (b).

(c) and (d) Bright filed images of HaCaT cells treated with or without GO after $48 \mathrm{~h}$. 